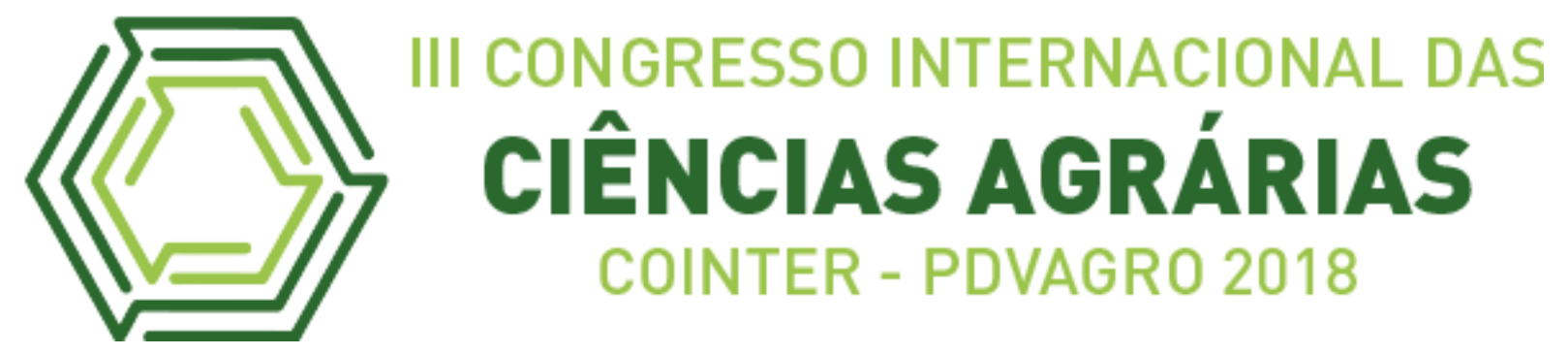

\title{
O IMPACTO DAS HORTAS ESCOLARES NA CONSTRUÇÃO DO PENSAMENTO ECOLÓGICO
}

\section{THE IMPACT OF THE SCHOOL GARDENS IN THE CONSTRUCTION OF THE ECOLOGICAL THINKING}

\author{
Apresentação: Relato de Experiência \\ Glaydson Jhonnys Queiroz Xavier ${ }^{1}$; Ana Paula da Silva Santos ${ }^{2}$; Maria José \\ Cavalcante Silva. ${ }^{3}$; Adjair José da Silva ${ }^{4}$; Elias Inácio da Silva ${ }^{5}$ \\ DOI: https://doi.org/10.31692/2526-7701.IIICOINTERPDVAGRO.2018.00752
}

\section{Introdução}

"O homem não é nada além daquilo que a educação faz dele" (KANT). O filósofo Immanuel Kant ressalta em sua famosa frase a importância da educação na formação de caráter de cada indivíduo. A escola é uma importante base para a formação do caráter humano e, para muitos, é a única base para uma série de conhecimentos, entre eles, o cuidado com o meio ambiente, ecologia e saúde.

Nesse contexto, tendo em vista a importância das escolas para formação pessoal da sociedade, o projeto de implantação de hortas escolares, nesse caso hortas orgânicas, visa contribuir na formação de saber dos envolvidos, incentivando a reflexão e iniciativas de práticas ecológicas e saudáveis.

"Em relação às hortaliças, com base em dados disponíveis na literatura especializada, o consumo de fungicidas atingiu uma área potencial de aproximadamente 800 mil hectares." (RIBEIRO, 2014, p.5).

“O processo de ecologização da agricultura consiste na introdução de novas práticas, mais respeitosas com o ambiente, em sintonia com o novo paradigma da sustentabilidade e o desenvolvimento sustentável." (COSTABEBER, 2000, p.01).

Entende-se, portanto, que novas práticas devem ser criadas urgentemente para combater a expansão do uso de agrotóxicos, criando assim uma frente contra esses venenos

\footnotetext{
${ }^{1}$ Bacharel em Agronomia, IFPE, Vitória, Glaydson766@gmail.com

${ }^{2}$ Bacharel em Agronomia, IFPE, Vitória, Anapaula.silva@hotmail.com

${ }^{3}$ Bacharel em Agronomia, IFPE, Vitória, Janecavalcante18@gmail.com

${ }^{4}$ Engenheiro Agrônomo, IFPE, Vitória, Adjairsilva.agronomia.ifpe@gmail.com

${ }^{5}$ Dr. Engenheiro Agrônomo, IFPE, Vitória, Elinasi.silva@gmail.com
} 
que estão cotidianamente na mesa dos brasileiros e criar com isto um pensamento ecológico.

As hortas escolares se encaixam perfeitamente na prática de ecologização.

\section{Relato de Experiência}

Assim, no dia 13 de setembro de 2018 o Programa Despertando Vocações para as Ciências Agrárias (PDVAgro) - Grupo de Trabalho: Hortas (GT de Hortas) - realizou a implantação de uma horta escolar na instituição de ensino EREM Cleto Campelo situada na cidade de Gravatá, no estado de Pernambuco.

As atividades tiveram início pela manhã no Instituto Federal de Educação Ciência e Tecnologia de Pernambuco (IFPE), Campus Vitória de Santo Antão, com a organização dos materiais necessários, entre eles: esterco caprino, enxadas, mudas das hortaliças, e o deslocamento para a cidade de Gravatá PE.

A recepção do GT pela escola foi organizada pelos coordenadores da instituição, os quais mostraram brevemente a escola e o local para desenvolvimento das atividades propostas. Para escolha do local alguns critérios foram levados em conta pelo grupo de trabalho, como, por exemplo, a disponibilidade de sol e a possibilidade de acesso dos estudantes e funcionários a área, logo, o local escolhido foi ao lado da quadra poliesportiva da escola.

Após organização e análise do planejamento proposto, o GT começou as atividades realizando a limpeza da área, retirando plantas espontâneas e lixo, em seguida houve o preparo do solo, introdução do adubo na terra, montagem dos canteiros e a compostagem dos canteiros (neste caso foi usada uma cobertura vegetal morta).

Foram montados 2 canteiros retangulares e pequenos canteiros com pneus usados (figura 1) para mostrar a possibilidade de reaproveitamento de materiais e a possibilidade de plantas hortaliças em pequenos espaços.

Por fim, foi feita uma parte teórica com os alunos e funcionário (figura 2), explicando a ideologia do programa, os benefícios de cultivar sua própria comida livrando-a de produtos químicos e os cuidados necessários para manutenção dos canteiros. Após os devidos informes sobre o procedimento para plantar, o transplante das mudas e plantio das sementes foi realizado (Figura 3).

As espécies plantadas foram: Couve de Folha (Brassica oleracea), Alface (Lactuca sativa) e Cebolinha (Allium schoenprasum). 
As atividades tiveram fim por volta da 16horas, hora na qual o grupo de trabalho retornou ao campus.

As figuras 4 e 5 mostram o progresso das hortaliças após um mês de cultivo, tanto os funcionários quanto os estudantes vêm se empenhando no manejo da horta, desde o momento da implantação. Ver que o trabalho está progredindo é realmente uma fonte inspiração.

Figura 1 Canteiros prontos Fonte: GT Figura 2 Parte teórica Fonte: GT

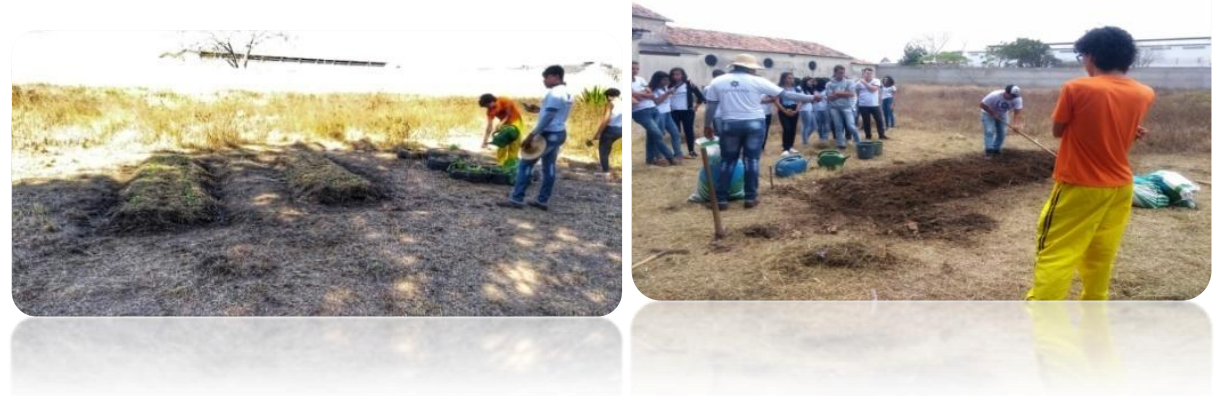

Figura 3 Plantio Fonte: GT
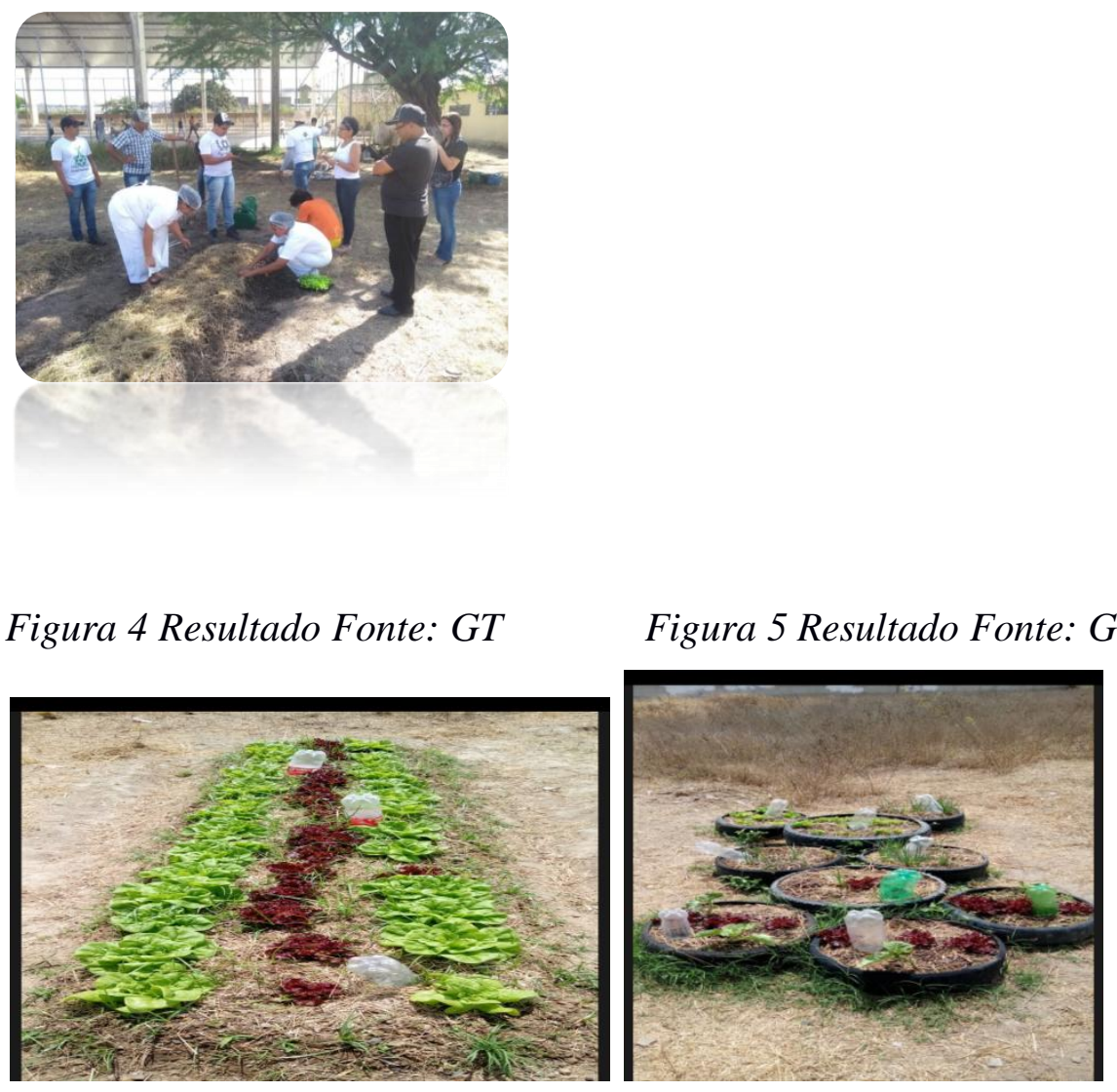


\section{Considerações}

Ter a oportunidade de trabalhar em um projeto tão singelo, mas que pode mudar a vida das pessoas não tem preço, é notória a mudança que uma horta causa no ambiente escolar, tanto na estrutura estética quanto na energia positiva que hortaliças em desenvolvimento passam.

Causas que incentivam o cuidado com o meio ambiente e a educação alimentar devem sempre estar em vigor. Por isso, o grupo de trabalho se compromete a continuar com o projeto de implantações de hortas escolares. Construir uma horta é acessível para todos basta querer!

\section{Referências}

COSTABEBER, José Antônio; MOYANO, Eduardo. Transição agroecológica e ação social coletiva. Agroecológia e Desenvolvimento Rural Sustentável, v. 1, n. 4, p. 50-60, 2000.

KANT, Immanuel. Crítica da razão prática. Tradução de Artur Mourão. Lisboa: Edições 70, 1986.

RIBEIRO, Bianca Alves Lima; CAMELLO, Thereza Cristina Ferreira. Reflexões sobre o uso de agrotóxicos e suas consequências. Revista Sustinere, v. 2, n. 2, p. 27-35, 2014. 